\title{
Synthesis and Characterization of nZVI Grafted Alumina and Its Application for Fluoride Removal from Drinking Water: Equilibrium and Kinetics Study
}

\author{
Madhu Agarwal ${ }^{1 *}$, Swati Dubey ${ }^{1}$, Renu Bisht $^{1}$ \\ ${ }^{1}$ Department of Chemical Engineering, Malaviya National Institute of Technology, Jaipur, 302017, India \\ *Corresponding author, email: madhunaresh@gmail.com
}

Received: 16 December 2017, Accepted: 02 April 2018, Published online: 10 May 2018

\begin{abstract}
In the present study attempt was made to synthesize iron nanoparticles in the presence of alumina (Al-nZVI) by sodium borohydride reduction process. The composite adsorbent has been characterized using various analytical techniques such as scanning electron microscopy, Fourier transform infrared spectroscopy, X-ray diffraction and transmission electron microscopy which showed that iron nanoparticles were partially dispersed on alumina surface, with their diameter being in the range 40-100 $\mathrm{nm}$. The batch adsorption experiments were carried out to study the effect of different parameters. The maximum removal of fluoride was obtained at optimal condition of $\mathrm{pH} 5.0$ and dose $=1.8 \mathrm{~g} / \mathrm{L}$ and was observed to be $94 \%$ with contact time of 60 min at $40{ }^{\circ} \mathrm{C}$ and initial concentration of $2 \mathrm{mg} / \mathrm{L}$. The adsorption data fitted that pseudo second order kinetics and followed Langmuir isotherm model with maximum adsorption capacity of $10.06 \mathrm{mg} / \mathrm{g}$. Thermodynamic study revealed exothermic nature of adsorption.
\end{abstract}

Keywords

fluoride, iron nanoparticles, alumina, characterization, equilibrium

\section{Introduction}

Availability of safe water for consumption is one of the most important gifts to mankind. But, unfortunately, the increase in concentration of contaminants such as fluoride above the permissible limit in groundwater resources over the years has become a serious matter of concern in many countries such as China, India, Pakistan, Turkey, Iraq, Afghanistan, Mexico, and Thailand [1, 2]. The presence of fluoride in drinking water should be below $1.5 \mathrm{mg} / \mathrm{L}$ as prescribed by WHO [3]. Intake of fluoride is recommended for mineralization of bones and for constructing dental enamel. Excess of which causes dental fluorosis, enamel lose its shine and texture, skeletal fluorosis [4]. The bones and enamel contain high calcium content which attracts fluoride to a significant amount which gets deposited on the surface as calcium- fluorapatite crystal [5]. Human intake of fluoride is mainly from groundwater. Various minerals like fluorite, biotites, and rocks like granite, basalt, etc. are the primary source of fluoride. Industries of glass, ceramic production produces waste containing high fluoride concentration into discharge into water. In India various states namely Assam, Andhra Pradesh, Rajasthan, Delhi, etc. are found to have high fluoride concentration in water [6]. Various defluoridation techniques and treatments such as, adsorption, membrane processes, and electro-coagulation have been developed for solving the complicated health issues raised because of excessive fluoride in potable water [7]. However, as reported in literature, adsorption technology is the most preferred method of defluoridation for impoverished people and mostly living in developing countries [8]. Adsorption process is a simple but attractive technique because of its high removal efficiency, selectivity, high-quality effluent, as well as its cost-effectiveness [30,31]. Various adsorbents have been reported for the application of fluoride removal [9]. Natural adsorbents as well as clay and soil based adsorbents when used are not harmful after consumption in anyway, but their low capacity for fluoride removal compared to other means remains a challenge [10]. Alumina and aluminum based adsorbents have been extensively used for fluoride removal due to high affinity between aluminum and fluoride ions. Many attempts have been made to modify alumina for higher fluoride removal [11, 12]. Goswami and Purkait (2012) developed acidic alumina as adsorbent 
for water defluoridation and found it to be highly $\mathrm{pH}$ dependent with $94 \%$ fluoride removal efficiency at $\mathrm{pH}$ value of 4.4 [13]. A study conducted for fluoride removal by Kamble et al. (2010) on alumina with alkoxide origin reported defluoridation capacity varying from 3.14 to $0.59 \mathrm{mg} / \mathrm{g}$ for dosage varying from 0.5 to $8 \mathrm{~g} / \mathrm{L}$ [14]. Still, there were many drawbacks related to these adsorbents including disposal of depleted adsorbents and interference because of the vicinity of different anions may bring about competition for active sites on adsorbent. Also, the leaching of aluminium is one of the major concerns in the process. However, aluminum leaching into drinking water from adsorbents is fatal for human beings causing neurodegenerative diseases and aluminum has been linked with many forms of dementia as well as Alzheimer's diseases [15, 16]. Hence, the field potential of those adsorbents cannot be determined.

Nano-scale iron particles represent a new generation of environmental remediation technologies that could provide cost-effective solutions to some of the most challenging environmental clean-up problems [17]. Nano-scale iron particles have large surface areas and high surface reactivity. Equally important, they also provide enormous flexibility for in situ applications [18]. Nowadays zero valent iron nanoparticles have been identified as the potential adsorbent for removal of chlorinated solvents, organochlorine pesticides, polychlorinated biphenyls, organic dyes, and inorganic pollutants, heavy metal ions, tetracycline due to their higher surface to volume ratio, higher reactivity, small size and high adsorption capacity [19]. In a recent study, nZVI was prepared and applied to remove excessive fluoride from water [17]. The removal rate of fluoride reached $84 \%$ in 35 min with nZVI dosage of $0.6 \mathrm{~g} / 1$ and $\mathrm{pH} 4$. Overall, the results obtained indicate that nZVI could be effectively used for removal of fluoride from contaminated water. The use of zero valent iron nanoparticles (nZVI) for groundwater remediation is restricted due to their tendency of agglomeration, instability and difficulty in separation [21]. Both alumina and iron nanoparticles individually remove heavy metals and fluoride efficiently as reported by different authors [17-19, 22].

In the present study, alumina has been coated with nanoparticle ZVI (nZVI) and applied for fluoride removal. The tendency to aggregation results in rapid sedimentation and consequently limited mobility of the nanoparticles in the aquatic media [22]. The coating of nZVI on alumina prevents leaching of aluminium into treated water, prohibits aggregation of nZVI and enhances the ease of separation. Also, synthesizing iron nanoparticles in the presence of a solid matrix can lead to decreasing the tendency of aggregation of iron nanoparticles. This was verified by applying kaolinite and bentonite as solid materials in our previous studies [18, 23]. Alumina, being a widely available natural inorganic solid, that is stable over a wide range of geochemical conditions, could therefore be appropriate for this purpose.

The objective of the present study was to synthesize in-situ composite of iron nanoparticle and alumina by reduction of ferric chloride on alumina (Alumina-nZVI). The synthesized adsorbent was characterized by different analytical techniques: scanning electron microscopy (SEM), transmission electron microscopy (TEM) and Fourier transform infrared spectroscopy (FTIR). The composite adsorbent has been used for fluoride removal at different operating conditions such as contact time, temperature, adsorbent dose etc. Finally the residual fluoride concentration was determined using Fluoride ion meter. Adsorption kinetics was also evaluated by fitting the experimental data to three kinetic models. Langmuir, Freundlich and Tempkin isotherms were adopted for finding the adsorption mechanism and adsorption energy calculation was also done by calculating the thermodynamic parameters.

\section{Materials and Methods}

\subsection{Materials}

Reagent grade sodium fluoride $(\mathrm{NaF})$, ferric chloride $\left(\mathrm{FeCl}_{3} \cdot 6 \mathrm{H}_{2} \mathrm{O}\right)$, ethanol $\left(\mathrm{C}_{2} \mathrm{H}_{5} \mathrm{OH}\right)$, sodium borohydride $\left(\mathrm{NaBH}_{4}\right)$, hydrochloric acid $(\mathrm{HCl})$, sodium hydroxide $(\mathrm{NaOH})$, were purchased from Merck Limited, Mumbai for the study. Stock solution $(100 \mathrm{mg} / \mathrm{L})$ of fluoride was prepared by adding $0.221 \mathrm{~g}$ of sodium fluoride $(\mathrm{NaF})$ in $1000 \mathrm{ml}$ of deionized water and $\mathrm{pH}$ of prepared solutions was maintained by adding $0.1 \mathrm{M} \mathrm{HCl}$ and $0.1 \mathrm{M} \mathrm{NaOH}$. All the required solutions were prepared with deionized water for synthesis, dilution and adsorption study.

\subsection{Synthesis of Adsorbents}

\subsubsection{Synthesis of $\mathrm{nZVI}$}

For synthesis of zero-valent iron nanoparticles $0.5406 \mathrm{~g}$ of $\mathrm{FeCl}_{3} \cdot 6 \mathrm{H}_{2} \mathrm{O}$ in $4 / 1(\mathrm{v} / \mathrm{v})$ ethanol and water solution and the mixture is kept on magnetic stirrer for absolute mixing at normal conditions [20]. Then $0.1 \mathrm{M}$ solution of sodium borohydride (reducing agent) is prepared by adding $0.3783 \mathrm{~g}$ of $\mathrm{NaBH}_{4}$ to $100 \mathrm{ml}$ of deionized water. Solution of sodium borohydride was added drop-wise via burette to the mixture of iron. Tiny black particles appeared instantly on adding sodium borohydride. The solution was then centrifuged and supernatant was taken after 3 times 
of centrifugation. Synthesis of zero-valent iron was based on reduction of ferric chloride $\left(\mathrm{FeCl}_{3} \cdot 6 \mathrm{H}_{2} \mathrm{O}\right)$ with sodium borohydride $\left(\mathrm{NaBH}_{4}\right)$. The amount of zero-valent iron nanoparticles obtained was around $0.11 \mathrm{~g}$. The proposed reaction for preparation of zero valent iron was as follows: $4 \mathrm{Fe}^{3+}+3 \mathrm{BH}_{4}^{-}+9 \mathrm{H}_{2} \mathrm{O} \rightarrow 4 \mathrm{Fe}^{0}+3 \mathrm{H}_{2} \mathrm{BO}_{3}^{-}+12 \mathrm{H}^{+}+6 \mathrm{H}_{2}$.

\subsubsection{Synthesis of alumina-nZVI}

For the synthesis of zero-valent iron nanoparticles the solution of ethanol and water in the ratio of 9:1 (225 $\mathrm{ml}$ of ethanol and $25 \mathrm{ml}$ of deionized water) was prepared [21]. Further, $4.40706 \mathrm{~g}$ of $\mathrm{FeCl}_{3} .6 \mathrm{H}_{2} \mathrm{O}$ to $250 \mathrm{ml}$ of solution $(225 \mathrm{ml}$ ethanol $+25 \mathrm{ml}$ of deionized water) with $3 \mathrm{~g} / \mathrm{L}$ $\mathrm{Fe}^{3+}$ and $1 \mathrm{~g}$ of alumina were stirred at $30{ }^{\circ} \mathrm{C}$ for 24 hours. $2 \mathrm{wt} \%$ solution of sodium borohydride ( $2 \mathrm{~g}$ in $100 \mathrm{ml}$ of deionized water) were added. Sodium borohydride was added at once and due to this black color appeared. After that solution was stirred for 2 hours in nitrogen atmosphere to prevent oxidation of zero-valent iron nanoparticles. Ethanol solution was allowed to settle. Solution was then ultra-sonicated for $15 \mathrm{~min}$ and then centrifuged for $15 \mathrm{~min}$ to make sure that zero-valent iron nanoparticles was deposited to alumina, then solution was filtered and particles were washed three times with ethanol. This washing was key step as it prevented rapid oxidation unlike deionized water. The synthesized nanoparticles $(\sim 2.5 \mathrm{~g})$ were dried in oven for about 2 hour at $70{ }^{\circ} \mathrm{C}$. Fig. 1 shows the experimental setup for preparation of alumina-nZVI composite in laboratory and Fig. 2(a) and 2(b) shows the black alumina-nZVI composite just after reaction and alumina-nZVI composite in ethanol respectively.

\section{Characterization of ZVI nanoparticles}

\subsection{Scanning electron microscope (SEM)} analysis coupled with Energy dispersive X-ray spectroscopy (EDS)

Fig. 3 shows SEM characterization of zero-valent iron and Alumina-nZVI composite. The SEM analysis was performed on the JOEL 2010 Instrument $(200 \mathrm{kv})$. For SEM, sample preparation was done by filtering the sample and drying for 2 hour at $70^{\circ} \mathrm{C}$. $5.2 \mathrm{mg}$ of sample was used for the analysis. Then dried particles were trapped on carbon tape. SEM images in Fig. 3(a) shows that iron nanoparticles synthesized were agglomerated and exhibits characteristic chain-like cluster morphology. Aggregated iron nanoparticles were dispersed on alumina support as shown

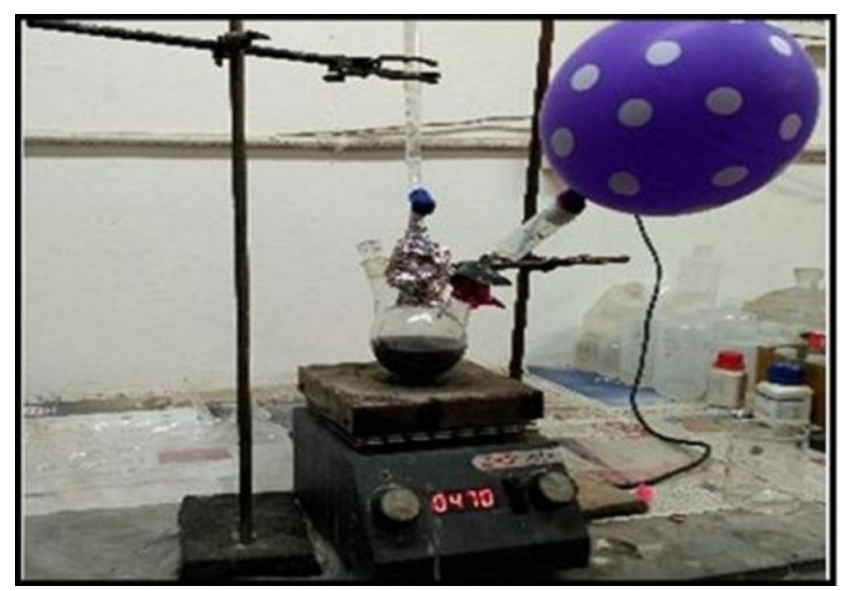

Fig. 1 Experimental setup for preparation of alumina-nZVI composite in laboratory

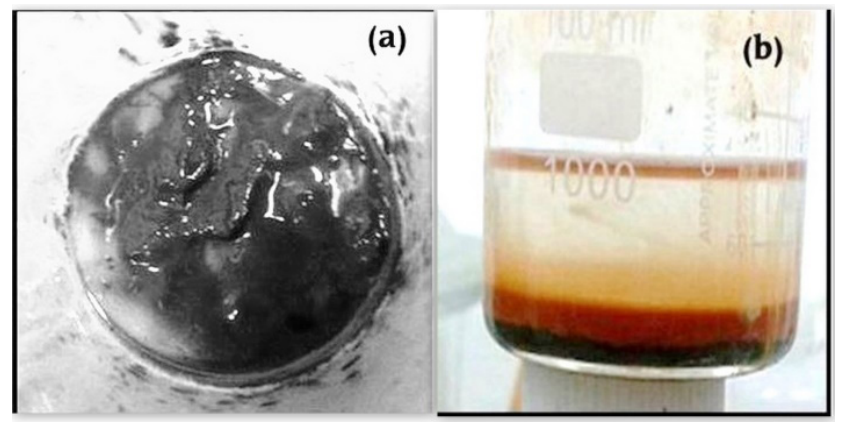

Fig. 2 Preparation of alumina nZVI composite (a) Black alumina-nZVI just after reaction, (b) alumina-nZVI in ethanol

in Fig. 3(b) [22]. The agglomeration expectedly decreased with increase of dispersion and mechanical strength of nZVI when alumina was used as the supporting material. It can be clearly seen from EDS analysis of Alumina-nZVI that Fe is present on the surface of alumina (Fig. 3(c)).

\subsection{X-Ray diffraction analysis (XRD), Fourier} transform infrared spectroscopy (FTIR), Transmission electron microscopy (TEM)

Fresh sample of Alumina-nZVI composite was prepared and XRD analysis was carried out. $0.1 \mathrm{~g}$ of sample was used for the analysis. From Fig. 4(a), presence of iron in its zero valent state was confirmed due to the reflection obtained at $2 \Theta=44.9^{\circ}[19,22]$. The peaks at $25.6^{\circ}, 27.09^{\circ}, 35.1^{\circ}, 36.2^{\circ}$, $37.79^{\circ}, 43.3^{\circ}, 52.56^{\circ}, 57.5^{\circ}, 66.5^{\circ}, 68.2^{\circ}, 76.9^{\circ}$ corresponded to peaks of alumina $[22,25]$. The FTIR spectra of alumina and the synthesized zero-valent iron supported on alumina were recorded in the transmission mode at room temperature (Fig. 4(b)). $0.9 \mathrm{mg}$ of sample was used for the analysis. Alumina and nZVI on alumina was subjected to IR spectroscopic analysis using infrared spectrophotometer in the 

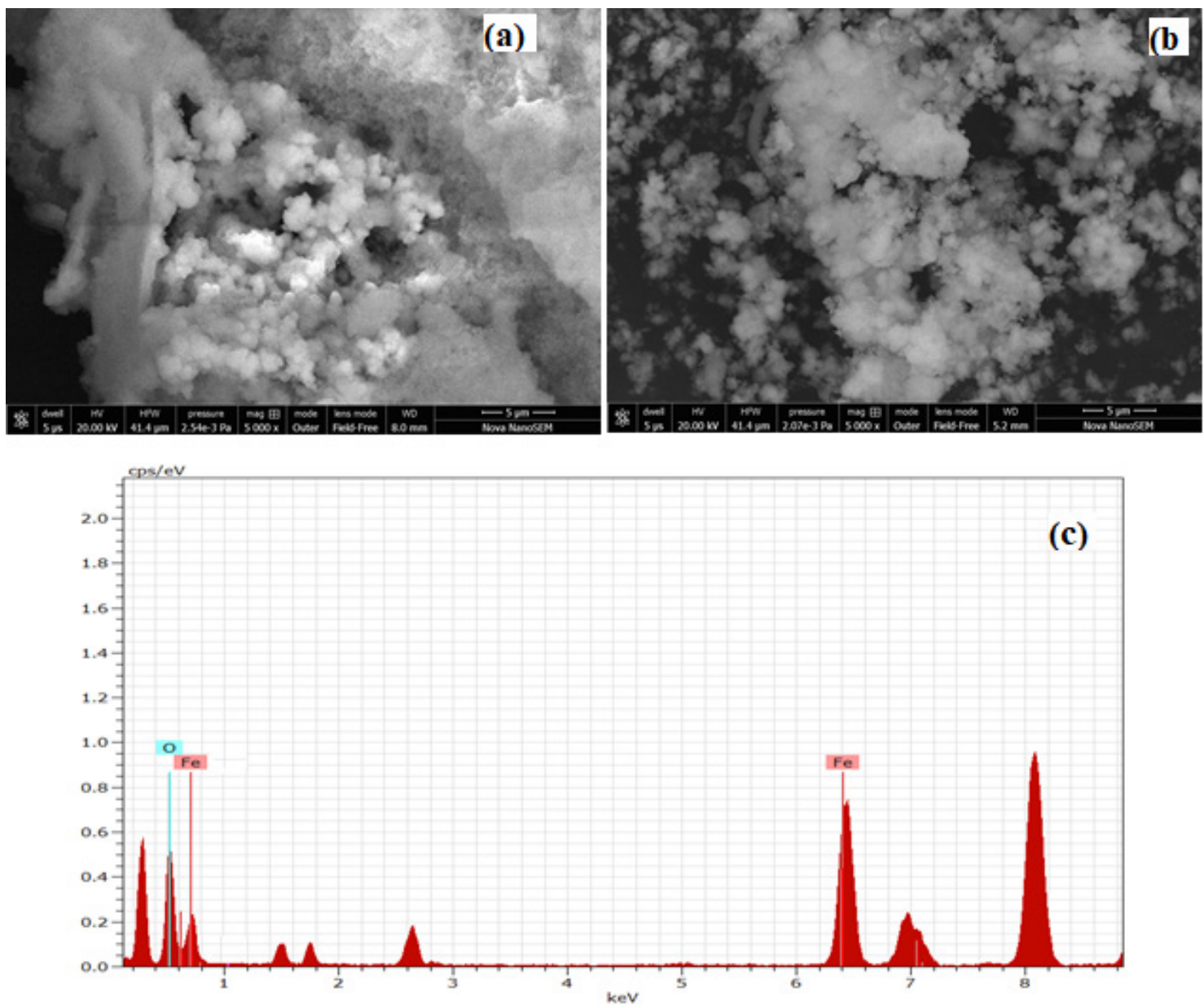

Fig. 3 SEM images of (a) Alumina-nZVI composite (b) nZVI (c) EDS analysis of Alumina-nZVI composite
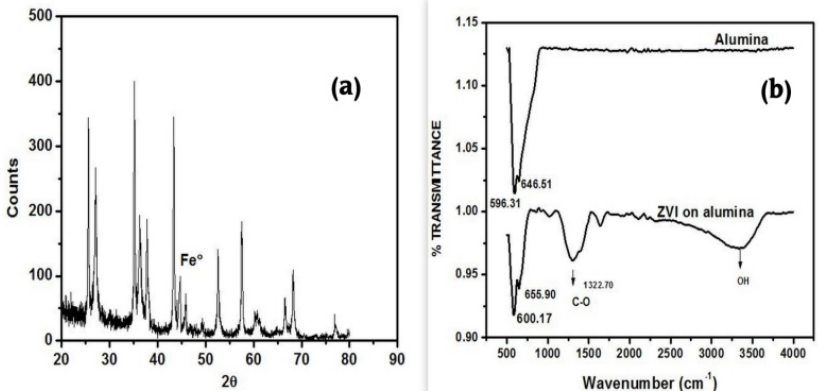

Fig. 4 (a) XRD analysis of Alumina-nZVI composite (b) FTIR spectra of alumina support and nZVI on alumina

range $500 \mathrm{~cm}^{-1}$ to $4000 \mathrm{~cm}^{-1}$. FTIR results showed that bands at $646.51 \mathrm{~cm}^{-1}$ and $593.31 \mathrm{~cm}^{-1}$ shifted to the higher wavenumber values $655.90 \mathrm{~cm}^{-1}$ and $600.17 \mathrm{~cm}^{-1}$ respectively. This shift was might be due to the coordinate bond between alumina and iron [24]. Peaks in the spectra of nZVI on alumina were between $3200 \mathrm{~cm}^{-1}$ to $3600 \mathrm{~cm}^{-1}$ and showed broad and strong peak of $\mathrm{OH}$ stretch bond. Further, peak at $1322.70 \mathrm{~cm}^{-1}$ showed C-O stretch [25]. TEM analysis was used to analyze the material constituents (Fig. 5). $2.5 \mathrm{mg}$ of sample was used for the analysis. The sample was dispersed in ethanol using an ultrasonic bath. Then, a drop of the dispersion was applied to a holey carbon TEM support grid and excess solution was blotted off by a filter paper. TEM image showed a composite layered structure comprised of a dense metallic center enclosed by a thin layer of iron-oxide material that surrounded the $\mathrm{Fe} 0$ core and preserved it against further oxidation [26]. As shown in Fig. 5, the HR-TEM analysis performed in this study supported this view with the shell. The presence of high-resolution fringes in the shell image indicated that the shell was crystalline.

\section{Adsorption Experiments}

The batch experiments were carried out in $250 \mathrm{ml}$ Erlenmeyer flask with $100 \mathrm{ml}$ of F- solution shaken in the incubator shaker at $180 \mathrm{rpm}$ to determine optimum dose and equilibrium time, while all the standard solution were prepared in the volumetric flask. F solution of 

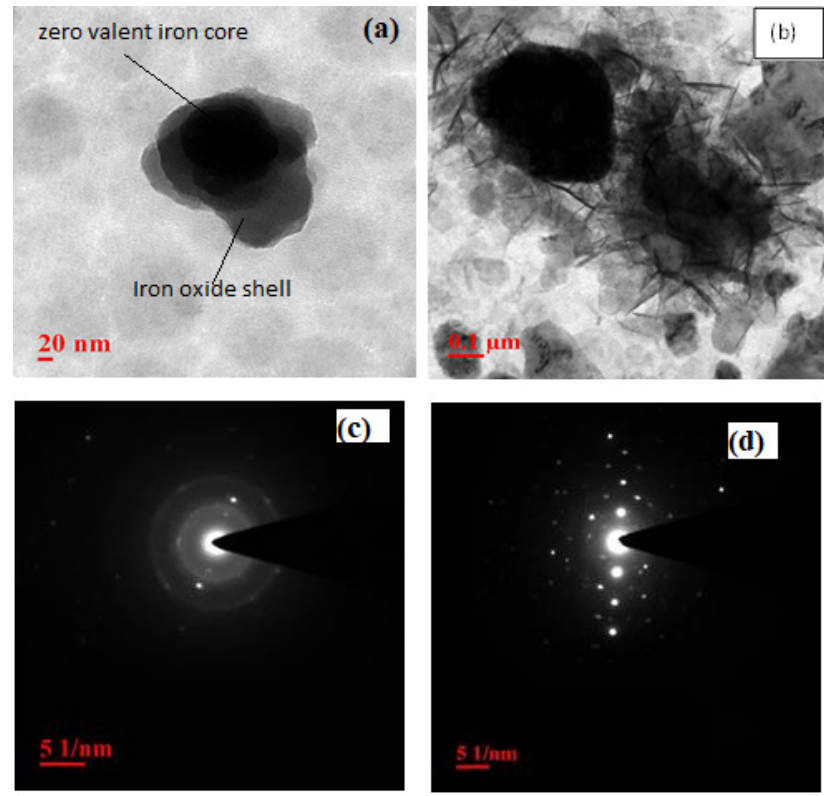

Fig. 5 (a) TEM images of nZVI nanoparticles showing a core-shell structure comprised of a dense metallic center and a thin, continuous oxide skin (b) nZVI electron diffraction pattern, (c) alumina-nZVI supported on and (d) alumina-nZVI on electron diffraction pattern.

concentration $2,4,6,8$, and $10 \mathrm{mg} / \mathrm{L}$ were prepared by diluting the stock solution. Contact time was varied from $15 \mathrm{~min}$ to 120 minutes and adsorbent dose was varied from 0.1 to $2 \mathrm{~g} / \mathrm{L}$ with initial concentration of $10 \mathrm{mg} / \mathrm{L}$. $\mathrm{pH}$ was maintained at $7 \pm 0.3$ and $5 \pm 0.3$ respectively by adding $0.1 \mathrm{M} \mathrm{HCl}$ and $0.1 \mathrm{M} \mathrm{NaOH}$. Required adsorbent dose was added in $10 \mathrm{mg} / \mathrm{L}$ solution $(100 \mathrm{ml})$ of $\mathrm{F}$ - and stirred at speed of $180 \mathrm{rpm}$. After equilibrium, the solution was filtered, and the filtrate was analyzed for residual fluoride by atomic absorption spectroscopy (AAS). The amount of fluoride adsorbed qe $(\mathrm{mg} / \mathrm{g})$ and \% removal was calculated using the following equations:

$q_{e}=\left(C_{i}-C_{e}\right) *(V / W)$

$\%$ Removal $=\left(C_{i}-C_{e}\right) / C_{e} \times 100$,

where $q_{e}$ is the adsorption capacity ( $\mathrm{mg} / \mathrm{g}$ ) of the adsorbent at equilibrium, $C_{i}$ and $C_{e}$ are initial and equilibrium concentration of fluoride; $\mathrm{V}$ is the volume of fluoride solution and $\mathrm{W}$ is the weight of adsorbent added.

\section{Effect of parameters}

Experiments have been performed in triplicate to study the effect of different operating parameters. Effect of process variables on fluoride removal has been described with the help of following Figs. 6-10.

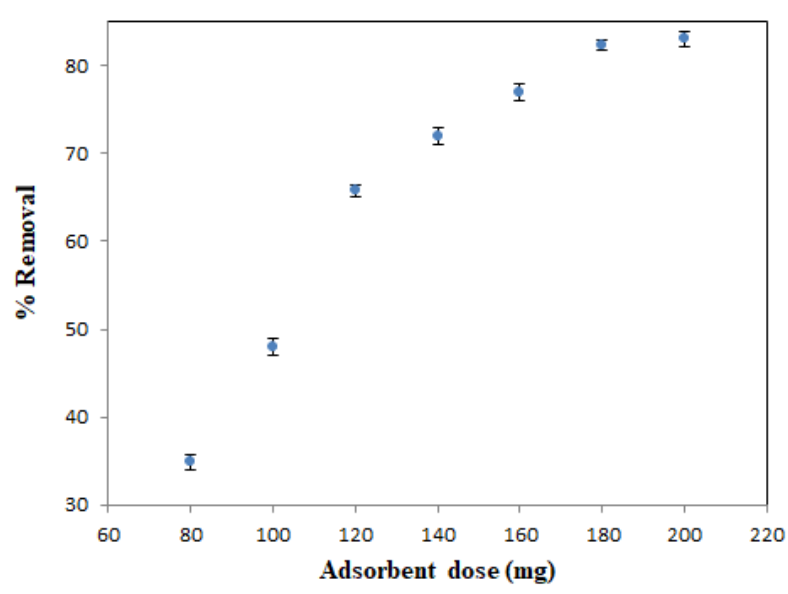

Fig. 6 Effect of adsorbent dose on removal of Fluoride at initial concentration $=10 \mathrm{mg} / \mathrm{L}$, contact time $=120 \mathrm{~min}, \mathrm{pH}=5$ and temperature $=40^{\circ} \mathrm{C}$, agitation speed $=180 \mathrm{rpm}$

\subsection{Effect of adsorbent dose}

Effect of adsorbent dose was studied by varying adsorbent dose from $80 \mathrm{mg}$ to $200 \mathrm{mg}$ at initial concentration of $10 \mathrm{mg} / \mathrm{L}$, contact time of $120 \mathrm{~min}$, at $\mathrm{pH}$ of 5 and temperature of $40{ }^{\circ} \mathrm{C}$. It was observed that as the adsorbent dose increases from $80 \mathrm{mg}$ to $220 \mathrm{mg}$ the removal of fluoride increases due to the availability of the adsorption sites. On further increase in adsorbent dose, no significant change in fluoride removal was observed. From Fig. 6, it was clear that fluoride removal increased from $35 \%$ to $82 \%$ as adsorbent dose was increased from $80 \mathrm{mg}$ to $200 \mathrm{mg}$.

\subsection{Effect of initial concentration and adsorption capacity}

Batch experiments were performed to determine the effect of initial concentration $(2,4,6,8 \mathrm{mg} / \mathrm{L})$ on fluoride removal at contact time of $120 \mathrm{~min}, \mathrm{pH}$, and temperature of $40{ }^{\circ} \mathrm{C}$, agitation speed of $180 \mathrm{rpm}$ and adsorbent dose of $200 \mathrm{mg}$. As shown in Fig. 7, fluoride removal decreased from $94.4 \%$ to $82.1 \%$ as initial concentration increased from $2 \mathrm{mg} / \mathrm{L}$ to $10 \mathrm{mg} / \mathrm{L}$ due to the limited number of sites available for adsorption. Initially, for low fluoride concentration the available adsorption sites were more, thus the sufficient interaction was possible between adsorbent and adsorbate. However, at high fluoride concentration the number of active sites available was not sufficient to adsorb all the fluoride ions present in the solution resulting in decrease in fluoride removal. However, the adsorption capacity increased from $0.5 \mathrm{mg} / \mathrm{g}$ to $4.0 \mathrm{mg} / \mathrm{g}$ with increase in initial concentration from $2 \mathrm{mg} / \mathrm{g}$ to $10 \mathrm{mg} / \mathrm{g}$. 

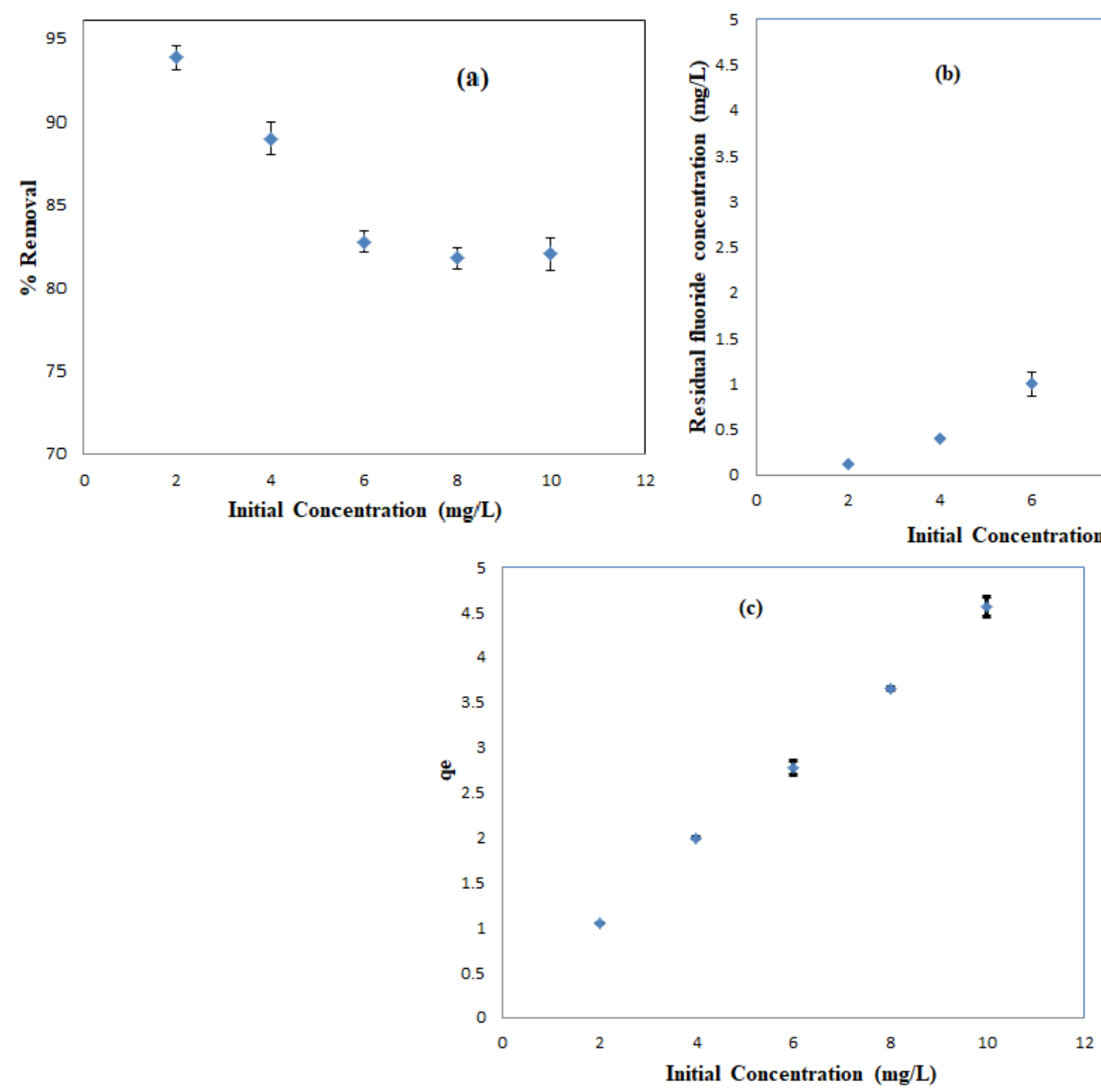

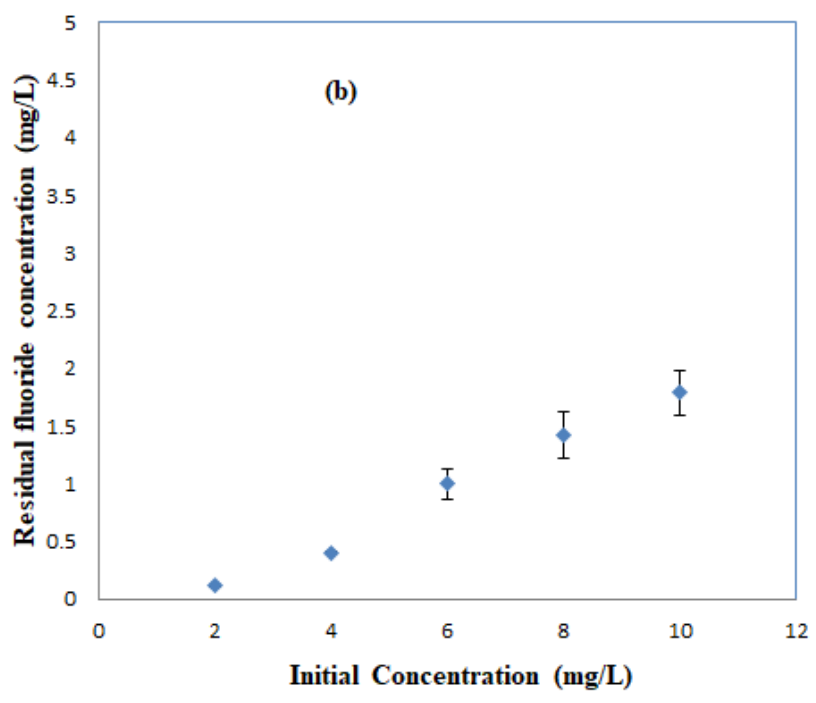

Fig. 7 Effect of initial concentration on (a) Fluoride removal percentage (b) Residual fluoride (c) Adsorption capacity at contact time $=120$ min, $\mathrm{pH}=5$, temperature $=40^{\circ} \mathrm{C}$, adsorbent dose $=200 \mathrm{mg}$, agitation speed $=180 \mathrm{rpm}$

\subsection{Effect of contact time}

To determine effect of contact time on fluoride removal, batch experiments were performed at initial concentration of $10 \mathrm{mg} / \mathrm{L}, \mathrm{pH} 5$, temperature of $40^{\circ} \mathrm{C}$, adsorbent dose of $200 \mathrm{mg}$ and agitation speed of $180 \mathrm{rpm}$. Fig. 7, shows the effect of contact time from $15 \mathrm{~min}$ to $135 \mathrm{~min}$ on removal of fluoride. The fluoride removal increased with time till the first 60 minute but after that it became constant. This was because of the availability of the adsorption sites in the beginning of the adsorption process but with increase in the time, available adsorption sites decreased.

\subsection{Effect of $\mathrm{pH}$}

Fig. 9 shows the effect of initial $\mathrm{pH}$ on the removal of fluoride at initial concentration of $10 \mathrm{mg} / \mathrm{L}$, temperature of $40{ }^{\circ} \mathrm{C}$, adsorbent dose of $200 \mathrm{mg}$ and agitation speed of
$180 \mathrm{rpm}$. It was observed that fluoride removal increased from $43 \%$ to $83 \%$ in increasing $\mathrm{pH} 3$ to 5 but after $\mathrm{pH} 5$ removal decreased. The dependency of removal on $\mathrm{pH}$ could be explained by speciation chemistry of the pollutant ions.

\subsection{Effect of temperature}

The effect of temperature on fluoride removal was studied by varying operating temperature from $20{ }^{\circ} \mathrm{C}$ to $70{ }^{\circ} \mathrm{C}$ keeping other parameters at initial concentration $=$ $10 \mathrm{mg} / \mathrm{L}$, contact time $=120 \mathrm{~min}$, adsorbent dose $=200 \mathrm{mg}$ and agitation speed $=180 \mathrm{rpm}$. Fig. 10 shows that the percent removal increases from $43 \%$ to $82 \%$ on increasing temperature from $20{ }^{\circ} \mathrm{C}$ to $40{ }^{\circ} \mathrm{C}$ but after $40{ }^{\circ} \mathrm{C}$ fluoride/ removal decreased. It was observed that low temperature favoured the fluoride removal due to the escape of fluoride ions from surface of adsorbent to the bulk phase. 


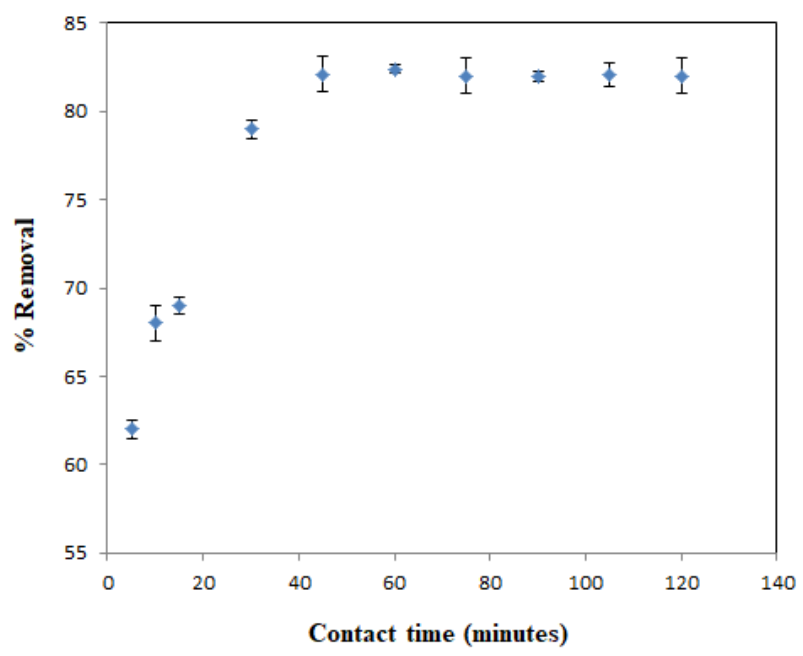

Fig. 8 Effect of contact time on Fluoride removal at initial concentration $=10 \mathrm{mg} / \mathrm{L}, \mathrm{pH} 5$, temperature of $40^{\circ} \mathrm{C}$, adsorbent dose of $200 \mathrm{mg}$ and agitation speed of $180 \mathrm{rpm}$.

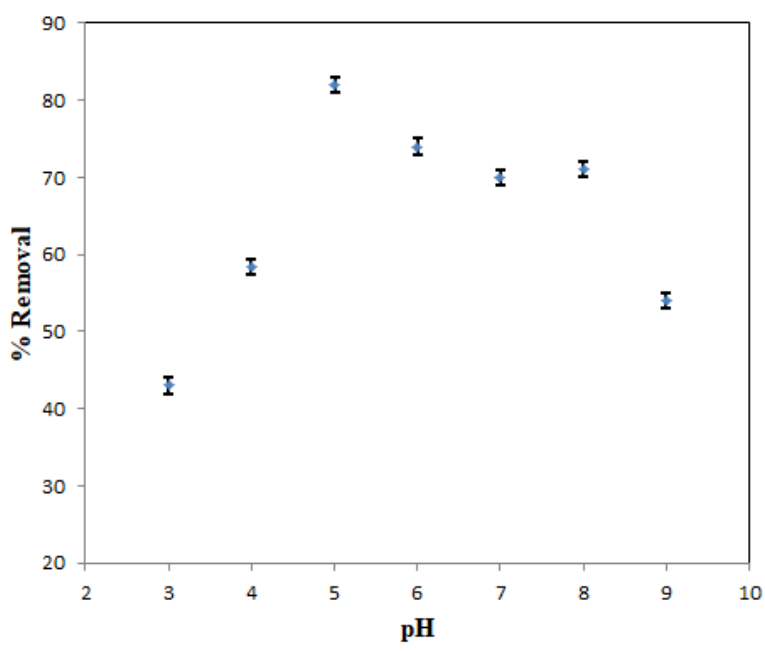

Fig. 9 Effect of $\mathrm{pH}$ on Fluoride removal at initial concentration $=$ $10 \mathrm{mg} / \mathrm{L}$, contact time $=120 \mathrm{~min}$, temperature $=40^{\circ} \mathrm{C}$, adsorbent dose $=200 \mathrm{mg}$ and agitation speed $=180 \mathrm{rpm}$

\section{Adsorption isotherm}

Adsorption isotherm was studied to better understand the relation between concentration of metal ion and adsorption capacity of the adsorbent (Fig. 11). It was very important to evaluate the isotherm for proper designing of adsorption system [27]. In the present study four isotherm model were studied and various constants were calculated (Table 1).

Langmuir isotherm model assumes the monolayer adsorption on the surface of the adsorbent after linearization the equation can be represented by,

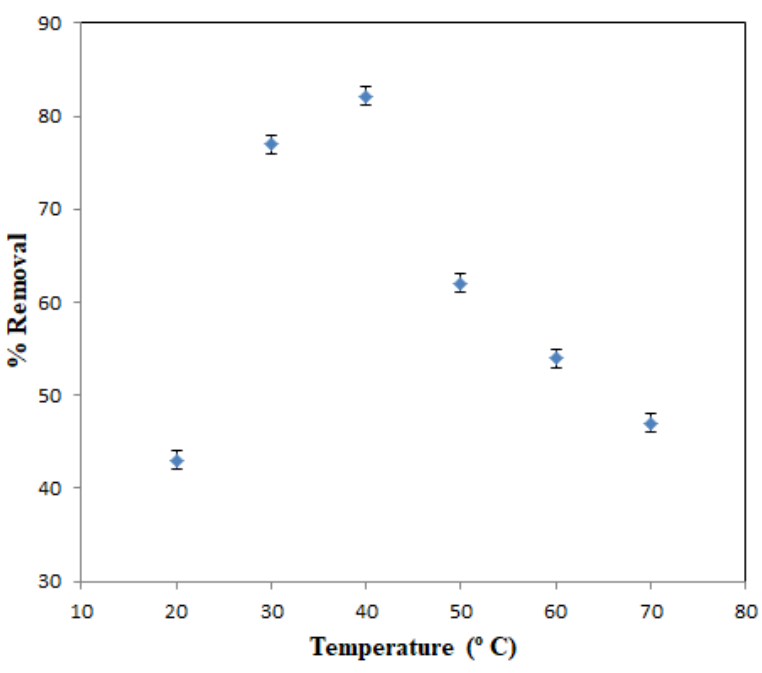

Fig. 10 Effect of temperature on \% Removal of Fluoride at initial concentration $=10 \mathrm{mg} / \mathrm{L}$, contact time $=120 \mathrm{~min}$, adsorbent dose $=200$ $\mathrm{mg}$ and agitation speed $=180 \mathrm{rpm}$

$\frac{c_{e}}{q_{e}}=\frac{C_{e}}{q_{L}}+\frac{1}{K_{L} q_{L}}$

Freundlich isotherm model describes the adsorption characteristics for the heterogeneous surfaces and the logarithmic form of equation is:

$\ln q_{e}=\ln K_{f}+\frac{1}{n} \ln C_{e}$.

Linear form of Temkin model equation is represented in following form;

$q_{e}=\frac{R T}{b_{T}} \ln A_{T}+\frac{R T}{b_{T}} \ln C_{e}$.

The nonlinear expression of D-R isotherm model can be illustrated as follows.

$\ln q_{e}=\ln X_{m}-K_{D R} \varepsilon^{2}$

$E=\frac{1}{\sqrt{2 K_{D R}}}$

where

$C_{e}$ - Equilibrium concentration

$q_{e}-$ Equilibrium adsorption capacity $(\mathrm{mg} / \mathrm{g})$

$K_{L}$ - Langmuir constant

$q_{L}-$ maximum adsorption capacity $(\mathrm{mg} / \mathrm{g})$

$K_{f}-$ Freundlich constant $(\mathrm{mg} / \mathrm{g})$

$1 / n$ - adsorption intensity

$R$ - the gas constant $(8.314 \mathrm{~J} /(\mathrm{mol} \mathrm{K}))$ : 

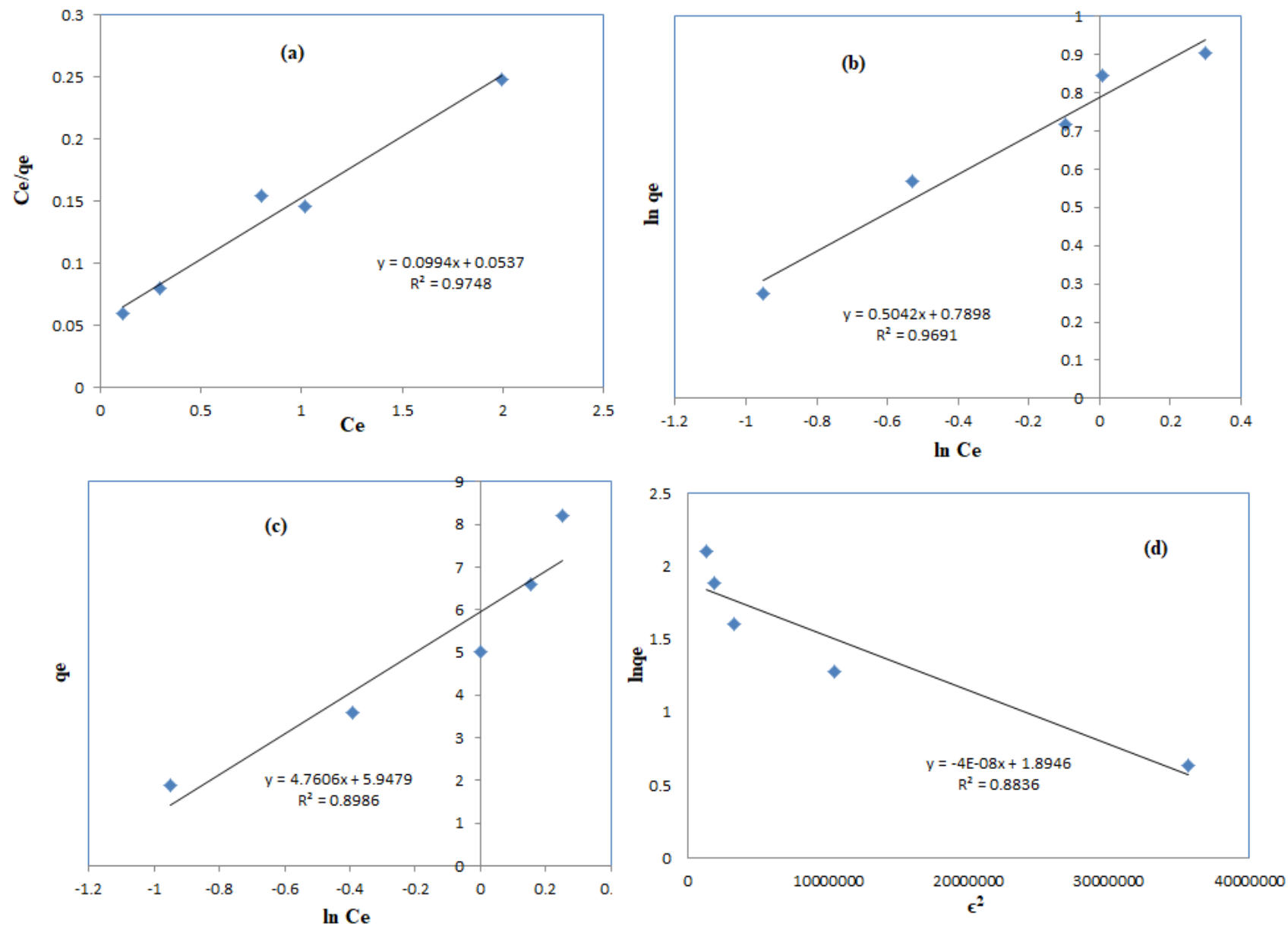

Fig. 11 Adsorption isotherm for adsorption of F on Alumina-nZVI composite (a) Langmuir isotherm (b) Freundlich isotherm

(c) Temkin isotherm (d) D-R isotherm

$T(K)$ - the absolute temperature

$b_{T} A_{T}-$ Temkin constant

$X_{m}$ - maximum adsorption capacity $(\mathrm{mg} / \mathrm{g})$

$K_{D R}-$ the adsorption energy constant $\left(\mathrm{mol}^{2} / \mathrm{kJ}^{2}\right)$

$\varepsilon-$ the Polanyi potential.

Table 1 Isotherm constants and parameters for fluoride adsorption

\begin{tabular}{lcccc}
\hline Model & Isotherm constants & $R^{2}$ & $\Delta q(\%)$ & SSE \\
\hline Langmuir & $R_{L}=0.0005$ & 0.9748 & 4.7 & 0.868 \\
& $q_{L}(\mathrm{mg} / \mathrm{g})=10.06$ & & & \\
Freundlich & $K_{f}=2.202$ & 0.969 & 5 & 1.33 \\
& $\mathrm{n}=1.98$ & & & \\
Temkin & $\mathrm{B}(\mathrm{J} / \mathrm{mol})=4.76$ & 0.898 & 9 & 2.479 \\
& $A_{T}(\mathrm{~L} / \mathrm{kg})=3.48$ & & & \\
Dubinin- & $\mathrm{E}(\mathrm{KJ} / \mathrm{mol})=0.0212$ & 0.956 & 9.9 & 5.2 \\
Radushkevich & $K_{D R}\left(\mathrm{~mol} / \mathrm{kJ}{ }^{2}\right)=0.0003$ & & & \\
& $X_{M}(\mathrm{mg} / \mathrm{g})=9.649$ & & & \\
\hline
\end{tabular}

Normalised standard deviation was calculated using the following equation [29]:

$\Delta q(\%)=100 *\left(\frac{\sqrt{\left(\sum\left(\frac{q_{\exp }-q_{c a l}}{q_{\exp }}\right)^{2}\right)}}{n-1}\right)$,

where $q_{\text {exp }}$ and $q_{\text {cal }}$ are experimental and calculated adsorption capacity values

$n=$ no. of data points.

Sum of square of errors was calculated using the equation:

$S S E=\sum\left(q_{\exp }-q_{c a l}\right)^{2}$.

In our study, Langmuir model fitted the adsorption data best as compared to the other three isotherms models for fluoride removal; it showed that the adsorption was monolayer. Value of $R_{L}$ was between 0 and 1 , thus 
it indicated favourable adsorption process. The value of Freundlich constant (n) was 1.98; it showed that adsorbent was suitable for removal of fluoride. The values of standard deviation and error were lowest for Langmuir isotherm. Low value of Temkin equilibrium binding constant indicated the presence of weak interaction between fluoride ions and adsorbent. The value of $\mathrm{E}$, mean free energy of adsorption was $\mathrm{E}<8 \mathrm{~kJ} / \mathrm{mol}$ and it indicated physical adsorption process (Table 1).

\section{Kinetic Model}

The experimental data obtained were fitted to the pseudo first, pseudo second and intra-particle diffusion model (Fig. 12). Kinetic constants and correlation of coefficient are tabulated in Table 2. To evaluate the rate limiting step for adsorption of fluoride by Alumina-nZVI composite, the kinetics were fitted to pseudo first order kinetic model, pseudo second order kinetic model and intra-particle diffusion [28].

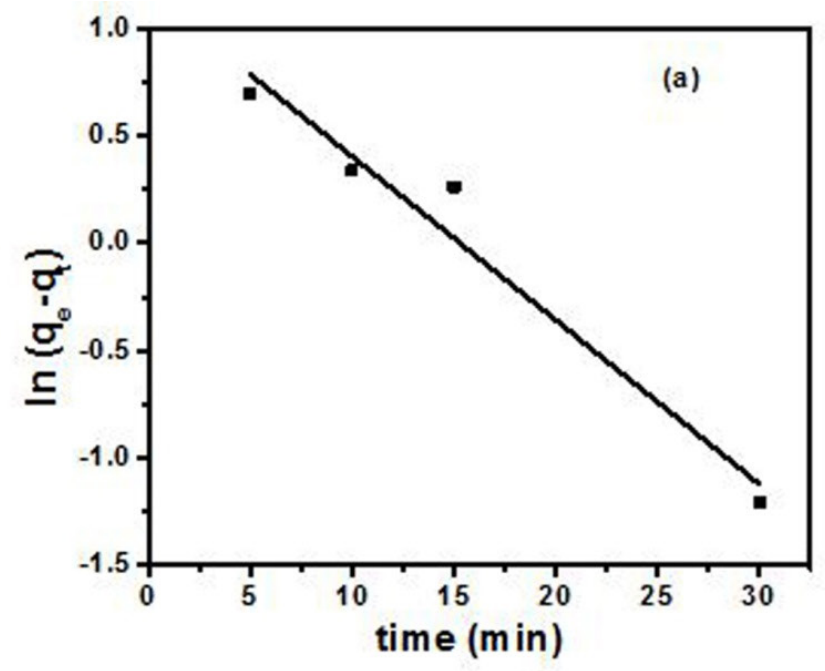

The pseudo first order equation can be represented as follows,

$\ln \left(q_{e}-q_{t}\right)=\ln q_{e}-k_{1} t$.

The pseudo second order equation, can be explained by following equation.

$\frac{t}{q_{t}}=\frac{1}{k_{2} q_{e}}+\frac{t}{q_{e}}$

$k_{2}$ represents adsorption rate constant for pseudo second order kinetics.

The intra-particle diffusion can be calculated by intra particle diffusion model,

$q_{t}=k_{i p d} t^{0.5}+C$

$q_{e}(\mathrm{mg} / \mathrm{g})$ : the adsorption capacity at equilibrium

$q_{t}(\mathrm{mg} / \mathrm{g})$ : the adsorption capacity at time $\mathrm{t}$

$t$ (min): contact time

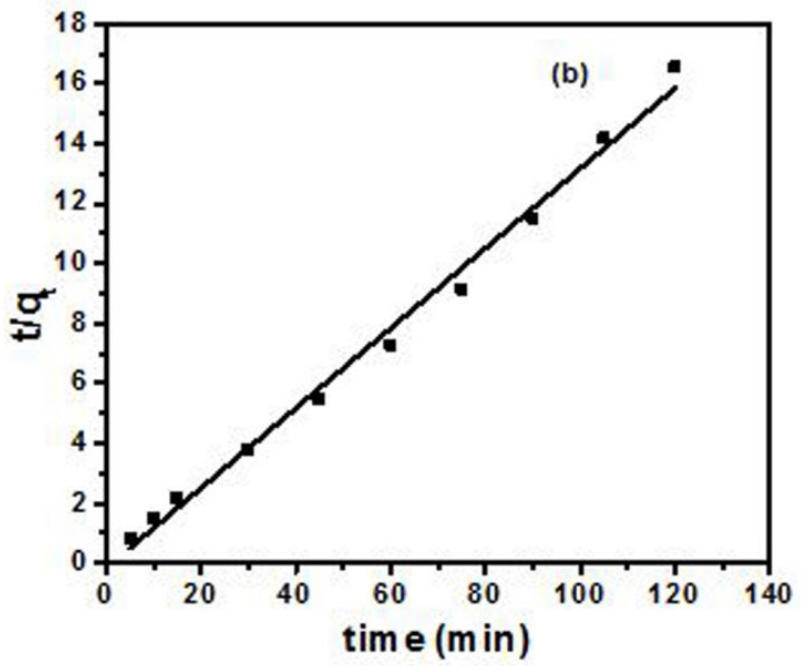

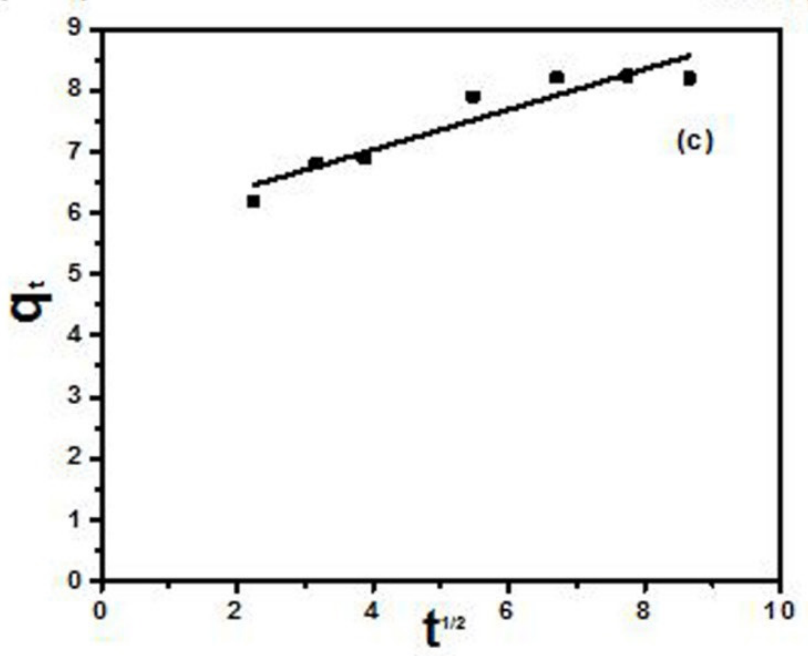

Fig. 12 Kinetic study for adsorption of F on nZVI-Al in single component system. (a) Pseudo first order kinetics for F, (b) Pseudo second order kinetics for F respectively, (c) Intra particle diffusion for $\mathrm{F}$. 


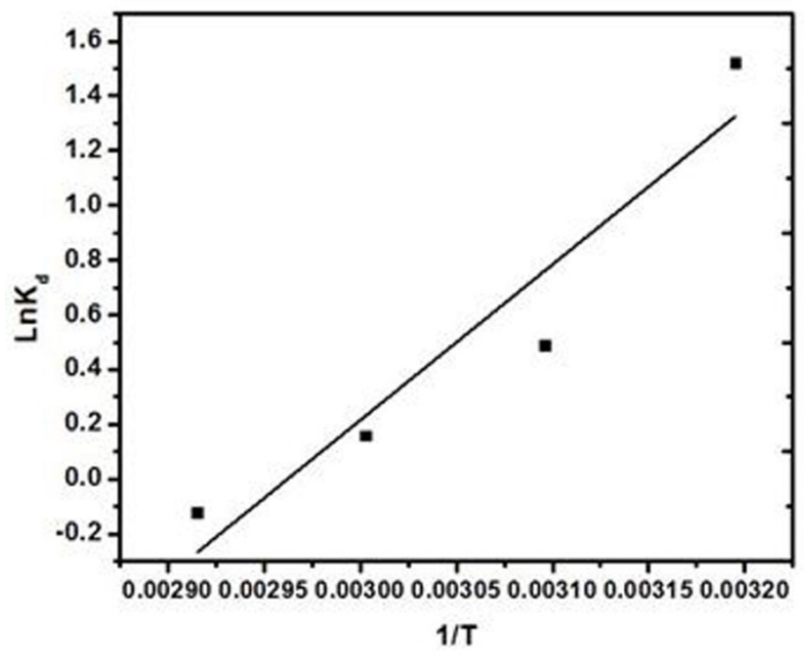

Fig. 13 The thermodynamic study plot of $\ln _{d}$ versus $1 / T$

Table 2 Kinetic parameters for adsorption of fluoride

\begin{tabular}{lccc}
\hline Model & $R^{2}$ & $q_{e}(\mathrm{mg} / \mathrm{g})$ & $\begin{array}{c}\text { Kinetic } \\
\text { parameters }\end{array}$ \\
\hline Pseudo first order & 0.9633 & 3.206 & $k_{1}=0.0762$ \\
$\begin{array}{l}\text { Pseudo second order } \\
\begin{array}{l}\text { Intra particle } \\
\text { diffusion }\end{array}\end{array}$ & 0.9928 & 7.496 & $k_{2}=0.8480$ \\
& 0.8973 & - & $k_{i p d}=0.3288$ \\
& & & $C=5.7143$ \\
\hline
\end{tabular}

$k_{1}(1 / \mathrm{min})$ : the rate constant of pseudo-first order adsorption $k_{2}(\mathrm{~g} / \mathrm{mg} \mathrm{min})$ : the rate constant of pseudo-second order adsorption.

Experimental data fits pseudo-second- order kinetics model well. For intra-particle diffusion to be rate limiting step, plot should be linear passing through the origin i.e. $\mathrm{C}=0$. In the present study the linear part of curve did not pass through the origin $(\mathrm{C} \neq 0)$. It indicated that the intra-particle diffusion was not the only rate-limiting step for adsorption of fluoride by Alumina-nZVI composite.

\section{Thermodynamic study}

The thermodynamic parameters calculated are tabulated in Table 3. In the present work, Vant Hoff equation was used to determine the values of $\Delta G^{\mathrm{o}}, \Delta H^{\mathrm{o}}$ and $\Delta S^{\mathrm{o}}$ as follows [29].

$$
\begin{aligned}
& \Delta G^{\circ}=\Delta H^{\circ}-T \Delta S^{\circ} \\
& \ln K_{d}=\frac{\Delta S^{\circ}}{R}-\frac{\Delta H^{\circ}}{R T} .
\end{aligned}
$$

Table 3 The thermodynamic parameters for fluoride adsorption on Alumina-nZVI composite

\begin{tabular}{lccc}
\hline Temperature $(\mathrm{K})$ & $\Delta G^{\circ}(\mathrm{KJ} / \mathrm{mol})$ & $\Delta H^{\circ}(\mathrm{KJ} / \mathrm{mol})$ & $\Delta S^{\circ}(\mathrm{KJ} / \mathrm{mol} \mathrm{K})$ \\
\hline 313 & -3.963 & & \\
323 & -1.3146 & -47.338 & -0.1402 \\
333 & -0.4417 & & \\
343 & 0.34291 & & \\
\hline
\end{tabular}

Table 4 Fluoride adsorption on alumina, nZVI and Alumina-nZVI composite in the present study

\begin{tabular}{llcc}
\hline & & $\%$ Removal & $q_{e}(\mathrm{mg} / \mathrm{g})$ \\
\cline { 2 - 4 } $\begin{array}{l}\text { Fluoride } \\
\text { removal } \\
\text { (Present Study) }\end{array}$ & Alumina & $37 \%$ & 3.5 \\
& $\begin{array}{l}\text { Alumina-nZVI } \\
\text { composite }\end{array}$ & $25 \%$ & 1.38 \\
& & $82 \%$ & 4.5 \\
\hline
\end{tabular}

$K_{d}$ is the equilibrium constant calculated as ratio of adsorbate concentration on surface $\left(C_{s}\right)$ and its equilibrium concentration $\left(C_{e}\right)$, $\mathrm{R}$ is universal Gas constant $(8.314 \mathrm{~J} / \mathrm{mol} / \mathrm{K})$ and $\mathrm{T}$ is absolute temperature. Negative value of $\Delta H^{\circ}$ indicated that the adsorption process was exothermic. Negative value of $\Delta G^{\circ}$ showed that the adsorption process was spontaneous and feasible. Negative value of $\Delta S^{\circ}$ indicated decrease in randomness at solid liquid interface (Table 3).

\section{Comparison of Adsorption Capacity}

Experiments were carried out for fluoride adsorption on alumina, zero valent iron nanoparticles and Alumina-nZVI composite. It was found from the present study that the fluoride removal trend was as follows: Alumina-nZVI composite $>$ Alumina $>$ nZVI. It was observed that for fluoride adsorption Alumina-nZVI composite adsorbent gave best removal. The adsorption capacity was higher for AluminanZVI composite as compared to the alumina and nZVI alone as shown in Table 4.

\section{Conclusions}

In this work alumina has been used as support material to disperse nano zero-valent iron particles and used as an efficient adsorbent for removal of $F$ from drinking water. From the characterization study (SEM, TEM, FTIR and XRD) of adsorbent Alumina-nZVI composite, it was clear that nZVI was successfully dispersed over alumina. The optimum $\mathrm{pH}$, temperature and contact time found were $5,40^{\circ} \mathrm{C}$ and 60 minutes respectively. Maximum adsorption was observed at initial concentration of $2 \mathrm{mg} / \mathrm{L}$. Kinetic study 
of adsorption showed that the experimental data followed pseudo second order kinetic model. Further, the adsorption data were fitted best to the Langmuir model. From the thermodynamic study it was found that the adsorption process was spontaneous and exothermic in nature.

\section{References}

[1] Ayoob, S., Gupta, A. K., Bhat, V. T. "A Conceptual Overview on Sustainable Technologies for the Defluoridation of Drinking Water", Critical Reviews in Environmental Science and Technology, 38(6), pp. 401-470, 2008. https://doi.org/10.1080/10643380701413310

[2] Meenakshi, Maheshwari, R. C. "Fluoride in drinking water and its removal", Journal of Hazardous Materials, 137(1), pp. 456463, 2006.

https://doi.org/10.1016/j.jhazmat.2006.02.024

[3] Agarwal, M., Dubey, S., Gupta, A. B. "Coagulation process for fluoride removal by comparative evaluation of Alum \& PACl coagulants with subsequent membrane microfiltration", International Journal of Environmental Technology and Management, 20(3-4), pp. 200-224, 2017.

https://doi.org/10.1504/IJETM.2017.089650

[4] Dubey, S., Agarwal, M., Gupta, A. B. "Advances in coagulation technique for treatment of fluoride-contaminated water: a critical review", Reviews in Chemical Engineering, 35(2), pp. 1-34, 2018. https://doi.org/10.1515/revce-2017-0043

[5] George, S., Pandit, P., Gupta, A. B. "Residual aluminium in water defluoridated using activated alumina adsorption - Modeling and simulation studies", Water Research, 44(10), pp. 3055-3064, 2010. https://doi.org/10.1016/j.watres.2010.02.028

[6] Jagtap, S., Yenkie, M. K., Labhsetwar, N., Rayalu, S. "Fluoride in Drinking Water and Defluoridation of Water", Chemical Reviews, 112(4), pp. 2454-2466, 2012.

https://doi.org/10.1021/cr2002855

[7] Dubey, S., Agarwal, M., Gupta, A. B. "Recent Developments in Defluoridation of Drinking Water in India", In: Singh, V., Yadav, S., Yadava, R. (eds.) Environmental Pollution, Water Science and Technology Library, Vol. 77, Springer International Publishing, Singapore, 2018, pp. 345-356.

https://doi.org/10.1007/978-981-10-5792-2_28

[8] Mouelhi, M., Marzouk, I., Hamrouni, B. "Optimization studies for water defluoridation by adsorption: application of a design of experiments", Desalination and Water Treatment, 57(21), pp. 9889-9899, 2015.

https://doi.org/10.1080/19443994.2015.1032363

[9] Mulugeta, E., Zewge, F., Johnson, C. A., Chandravanshi, B. S. "Aluminium hydro(oxide) - based (AO) adsorbent for defluoridation of drinking water: Optimisation, performance comparison, and field testing", African Journals Online, 41(1), pp. 121-128, 2015. https://doi.org/10.4314/wsa.v41i1.15

[10] Loganathan, P., Vigneswaran, S., Kandasamy, J., Naidu, R. "Defluoridation of drinking water using adsorption processes", Journal of Hazardous Materials, 248-249(1), pp. 1-19, 2013. https://doi.org/10.1016/j.jhazmat.2012.12.043

\section{Acknowledgement}

The authors would like to thank Material and research centre at MNIT Jaipur for providing assistance with SEM, XRD, TEM and FTIR analysis.

[11] Bhatnagar, A., Kumar, E., Sillanpää, M. "Fluoride removal from water by adsorption - A review", Chemical Engineering Journal, 171(3), pp. 811-840, 2011.

https://doi.org/10.1016/j.cej.2011.05.028

[12] Mondal, P., George, S. "A review on adsorbents used for defluoridation of drinking water", Reviews in Environmental Science and Bio/Technology, 14(2), pp. 195-210, 2015. https://doi.org/10.1007/s11157-014-9356-0

[13] Goswami, A., Purkait, M. K. "The defluoridation of water by acidic alumina", Chemical Engineering Research and Design, 90(12), pp. 2316-2324, 2012.

https://doi.org/10.1016/j.cherd.2012.05.002

[14] Kamble, S. P., Deshpande, G., Barve, P. P., Rayalu, S., Labhsetwar, N. K., Malyshew, A., Kulkarni, B. D. "Adsorption of fluoride from aqueous solution by alumina of alkoxide nature: Batch and continuous operation", Desalination, 264(1-2), pp. 15-23, 2010. https://doi.org/10.1016/j.desal.2010.07.001

[15] Alemu, S., Mulugeta, E., Zewge, F., Chandravanshi, B. S. "Water defluoridation by aluminium oxide-manganese oxide composite material", Environmental Technology, 35(15), pp. 1893-1903, 2014. https://doi.org/10.1080/09593330.2014.885584

[16] Wasana, H. M. S., Perera, G. D. R. K., De Gunawardena, P. S., Bandara, J. "The impact of aluminum, fluoride, and aluminum-fluoride complexes in drinking water on chronic kidney disease", Environmental Science and Pollution Research, 22(14), pp. 11001-11009, 2015. https://doi.org/10.1007/s11356-015-4324-y

[17] Fakhri, A., Adami, S. "Response Surface Methodology for Adsorption of Fluoride Ion Using Nanoparticle of Zero Valent Iron from Aqueous Solution", Chemical Engineering \& Process Technology, 4(5), pp. 4-9, 2013. https://doi.org/10.4172/2157-7048.1000161

[18] Shahwan, T., Üzüm, Ç., Eroğlu, A. E., Lieberwirth, I. "Synthesis and characterization of bentonite/iron nanoparticles and their application as adsorbent of cobalt ions", Applied Clay Science, 47(3-4), pp. 257-262, 2010. https://doi.org/10.1016/j.clay.2009.10.019

[19] Agarwal, M., Patel, D. "Modified Zero valent Iron (ZVI) Nanoparticles for Removal of Manganese from Water", International Journal of Environmental Research, 9(3), pp. 1055-1068, 2015. https://doi.org/10.22059/IJER.2015.993

[20] Liu, Y., Majetich, S. A., Tilton, R. D., Sholl, D. S., Lowry, G. V. "TCE Dechlorination Rates, Pathways, and Efficiency of Nanosclae Iron Particles with Different Properties", Environmental Science and Technology, 39(5), pp. 1338-1345, 2005. https://doi.org/10.1021/es049195r 
[21] Jain, A., Agarwal, M. "Kinetic equilibrium and thermodynamic study of arsenic removal from water using alumina supported iron nano particles", Journal of Water Process Engineering, 19, pp. 51-59, 2017. https://doi.org/10.1016/j.jwpe.2017.07.001

[22] Karabelli, D., Ünal, S., Shahwan, T., Eroğlu, A. E. "Preparation and characterization of alumina-supported iron nanoparticles and its application for the removal of aqueous $\mathrm{Cu}^{2+}$ ions", Chemical Engineering Journal, 168(2), pp. 979-984, 2011. https://doi.org/10.1016/j.cej.2011.01.015

[23] Üzüm, Ç., Shahwan, T., Eroğlu, A. E., Hallam, K. R., Scott, T. B., Lieberwirth, I. "Synthesis and characterization of kaolinite-supported zero-valent iron nanoparticles and their application for the removal of aqueous $\mathrm{Cu}^{2+}$ and $\mathrm{Co}^{2+}$ ions", Applied Clay Science, 43(2), pp. 172-181, 2009.

https://doi.org/10.1016/j.clay.2008.07.030

[24] Smedley, P. L., Kinniburgh, D. G. "A review of the source, behaviour and distribution of arsenic in natural waters", Applied Geochemistry, 17(5), pp. 517-568, 2002. https://doi.org/10.1016/S0883-2927(02)00018-5

[25] Gupta, V. K., Agarwal, S., Saleh, T. A. "Synthesis and characterization of alumina-coated carbon nanotubes and their application for lead removal", Journal of Hazardous Materials, 185(1), pp. 17-23, 2011. https://doi.org/10.1016/j.jhazmat.2010.08.053

[26] Schrick, B., Hydutsky, B. W., Blough, J. L., Mallouk, T. E. "Delivery Vehicles for Zerovalent Metal Nanoparticles in Soil and Groundwater", Chemistry of Materials, 16(11), pp. 2187-2193, 2004. https://doi.org/10.1021/cm0218108
[27] Ghorai, S., Pant, K. K. "Investigations on the column performance of fluoride adsorption by activated alumina in a fixed-bed", Chemical Engineering Journal, 98(1-2), pp. 165-173, 2004. https://doi.org/10.1016/j.cej.2003.07.003

[28] Jain, A., Agarwal, M. "Synthesising zero valent iron supported on alumina for removal of arsenic from drinking water", Interdisciplinary Environmental Review, 18(2), pp. 1-16, 2017. https://doi.org/10.1504/IER.2017.087912

[29] Ahmad, M. A., Ahmad Puad, N. A., Bello, O. S. "Kinetic, equilibrium and thermodynamic studies of synthetic dye removal using pomegranate peel activated carbon prepared by microwave-induced $\mathrm{KOH}$ activation", Water Resources and Industry, 6, pp. 18-35. 2014. https://doi.org//10.1016/j.wri.2014.06.002

[30] Cheng, J., Meng, X., Jing, C., Hao, J. "La ${ }^{3+}$ - modified activated alumina for fluoride removal from water", Journal of Hazardous Materials, 278, pp. 343-349, 2014. https://doi.org/10.1016/j.jhazmat.2014.06.008

[31] Duan, Y., Wang, C., Li, X., Xu, W. "Fluoride adsorption properties of three modified forms of activated alumina in drinking water Ying", Journal of Water and Health, 12(4), pp. 715-721, 2014. https://doi.org/10.2166/wh.2014.016 